$1 \quad$ Supporting Information for

\title{
2 Absorption enhancement of black carbon aerosols 3 constrained by mixing-state heterogeneity
}

4 Authors: Jinghao Zhai ${ }^{1}$, Xin Yang ${ }^{1 *}$, Ling $\mathrm{Li}^{2}$, Bin $\mathrm{Bai}^{3}$, Pengfei Liu ${ }^{3}$, Yuanlong Huang ${ }^{4}$, Tzung-

5 May Fu ${ }^{1}$, Lei Zhu ${ }^{1}$, Zhenzhong Zeng ${ }^{1}$, Shu Tao ${ }^{1,5}$, Xiaohui $\mathrm{Lu}^{2}$, Xingnan $\mathrm{Ye}^{2}$, Xiaofei Wang ${ }^{2}$, Lin

$6 \mathrm{Wang}^{2}$, Jianmin Chen ${ }^{2}$

$7{ }^{1}$ School of Environmental Science and Engineering, Southern University of Science and

8 Technology, Shenzhen 518055, China

$9 \quad{ }^{2}$ Shanghai Key Laboratory of Atmospheric Particle Pollution and Prevention, Department of

10 Environmental Science and Engineering, Fudan University, Shanghai 200433, China

11 35chool of Earth and Atmospheric Sciences, Georgia Institute of Technology, Atlanta, GA 30332,

$12 U S A$

$13{ }^{4}$ Division of Geological and Planetary Sciences, California Institute of Technology, Pasadena, CA

1491125, USA

$15{ }^{5}$ Laboratory for Earth Surface Process, College of Urban and Environmental Sciences, Peking 16 University, Beijing 100871, China 
$18 *$ To whom correspondence should be addressed.

19 Correspondence to: Xin Yang

20 Email: yangx@ sustech.edu.cn

21

22 Number of pages: 27

23 Number of figures: 11

24 Number of tables: 1

25 
27 In this work, aerosols were sampled with a $\mathrm{PM}_{2.5}$ cyclone positioned $2 \mathrm{~m}$ above the building roof 28 and were transferred to the instruments through a stainless steel pipe (0.25 inch ID, $6 \mathrm{~m}$ in length).

29 A pump was used to pull air through the sampling system at $30 \mathrm{~L} \mathrm{~min}^{-1}$, minimizing the particle 30 residence time in the sampling line. Silica gel driers were used at the sampling inlet and all the 31 instruments are place at room temperature $\left(22^{\circ} \mathrm{C}\right)$. Particles were sampled behind the inlet drier 32 maintained at $\sim 23 \% \mathrm{RH}$ during the sampling period.

33 The separation of volatile and less volatile particle components at specific temperatures was 34 achieved by laboratory-made thermodenuders (TD) set at $300{ }^{\circ} \mathrm{C}$. In this work, two sets of TDs 35 were utilized. One (TD1) was in series with the chemical and optical measurements, the other one 36 (TD2) was used in the particle mixing state measurements (Figure S1). Both TDs consist of a 37 heating tube (stainless steel, 1 inch OD, 0.875 inch ID, $50 \mathrm{~cm}$ in length) and an adsorption tube 38 (70 $\mathrm{cm}$ in length). The adsorption tube is surrounded by an annular bed of activated carbon to 39 adsorb the evaporated compounds. The flow rate through the TD1 was $1.6 \mathrm{~L} \mathrm{~min}^{-1}\left(1.5 \mathrm{~L} \mathrm{~min}^{-1}\right.$ to 40 the optical property measurements and $0.1 \mathrm{~L} \mathrm{~min}^{-1}$ to the chemical composition measurements), 41 corresponding to a particle residence time of $\sim 7.1$ seconds in the heating section. To maintain the 42 same residence time, a supplementary flow of $1.3 \mathrm{~L} \mathrm{~min}^{-1}$ was used for TD2 besides a flow of 0.3

$43 \mathrm{~L} \mathrm{~min}-1$ to the mixing state measurement system. A bypass line in parallel with the TD was used 44 as a reference for the number concentration of unheated particles. During the sampling, an actuated 
45 ball valve was upstream the TD1 and switched between bypass mode and TD mode on a 10 min

46 cycle. Though thermal desorption (TD) has been widely used to separate the coating and core

47 materials of particles, incomplete volatilization of non-BC materials could occur. However, in this

48 work, the ratio between the total amount of non-refractory residual material and $\mathrm{BC}$ (termed $\left.R_{\mathrm{BC}}\right)$

49 was large enough to substantially influence the calculated $E_{\text {abs }}$, and therefore potentially also the

50 measured $E_{\text {abs }}$.

51 Particle loss was calibrated to reduce the uncertainty brought by the thermophoretic forces and

52 diffusion during the heating process. Sodium chloride $(\mathrm{NaCl})$ aerosols produced by a single-jet

53 atomizer (Model 9302, TSI Inc.) were used to determine the transport efficiency ( $\eta$ ) in the TDs.

54 Dried $\mathrm{NaCl}$ particles were firstly selected by a differential mobility analyzer (DMA) to different

55 electric mobility diameters $\left(d_{\mathrm{p}}: 40,70,100,150,200,300\right.$, and $\left.350 \mathrm{~nm}\right)$. The number concentration

56 of size-selected $\mathrm{NaCl}$ particles passed through the TD line or bypass line was then detected by a

57 condensation particle counter (CPC). We determine the $\eta$ as the ratio of the number concentrations

58 of $\mathrm{NaCl}$ particles passing through the TD line to the bypass line (Figure S6). The measured $\eta$ were

59 used to correct the particle quantitative concentration in all the measurements.

60 


\section{Single-particle chemical composition.}

62 Chemical composition at the single-particle level was obtained by a single-particle aerosol mass

63 spectrometer (SPAMS, Hexin Analytical Instrument). Particles are first induced into the

64 aerodynamic focusing lens through a $0.1 \mathrm{~mm}$ critical orifice with a flowrate of $0.1 \mathrm{~L} \mathrm{~min}^{-1}$. Each

65 particle is accelerated to a size-dependent aerodynamic velocity by the aerodynamic focusing lens.

66 Then, monodispersed particles are irradiated by two orthogonally oriented continuous lasers $(\mathrm{Nd}$ :

67 YAG, $532 \mathrm{~nm}$ ) and the corresponding scatter lights are collected by two photomultiplier tubes

68 (PMT). The vacuum aerodynamic diameter of each particle is calculated according to the delay

69 time of PMT signals. When a particle arrives at the ion source region, a pulsed

70 desorption/ionization laser (Q-switched Nd: YAG, $266 \mathrm{~nm}$ ) is triggered to produce ion segments,

71 which are detected by a bipolar time-of-flight mass spectrometer. Both positive and negative mass

72 spectra are recorded for each single particle. In this work, the power of desorption /ionization laser

73 was set to $\sim 0.6 \mathrm{~mJ}$ per pulse. The aerodynamic diameter measurement is calibrated with curves

74 generated by monodisperse polystyrene latex spheres (Nanosphere size standards) with known

75 diameters $(0.2-2.0 \mu \mathrm{m})$.

76 All single particle mass spectra acquired are filtered by setting a minimum signal threshold of

7750 arbitrary units above the baseline for each mass-to-charge ratio $( \pm(1-250) \mathrm{m} / \mathrm{z})$. The resulting

78 peak lists and aerodynamic diameters are imported into Matlab (version R2019b). In this work, a

79 total number of 204,418 BC-containing particles were typically identified, accounting for about 
$8052 \%$ of all ionized particles. Parameters for ART-2a used in this work, such as vigilance factor,

81 learning rate, and iterations were $0.85,0.05$, and 20 , respectively.

82 In this work, the sum of all the non-BC signals relative to the sum of BC signals in single-

83 particle mass spectra (denoted non-BC/BC signal ratio) can reflect the non-BC/BC fractions.

84 During the sampling period, particles in each time slice (by hour) were treated as a population.

85 The variability in per-particle non-BC/BC signal ratios was quantified as the coefficient of

86 variation (standard variation relative to mean value) for particles in each population. Here the

87 adaption of coefficient of variation can effectively avoid the error brought by the different amounts

88 of sampled particles for different populations.

89 
91 An inhouse-built cavity ring-down spectrometer (CRDS) at $532 \mathrm{~nm}$ wavelength was in series with

92 an integrating nephelometer (Model 3563, TSI Inc.) to monitor extinction coefficient $\left(b_{\text {ext }}\right)$ and

93 scattering coefficient $\left(b_{\text {scat }}\right)$ of ambient aerosols. The absorption coefficient $\left(b_{\text {abs }}\right)$ is then obtained

94 by $b_{\text {ext }}$ subtracting $b_{\text {scat }}$. Two highly-reflective dielectric mirrors $(540 \mathrm{~nm}$ center wavelength,

$9599.999 \%$ reflectivity, 6 m radius of curvature, 0.8 inch in diameter, Los Gatos Research, Inc.) and

96 a stainless steel cell (76 cm in length) with two aerosol inlets at both ends and one outlet in the

97 middle formed the cavity. A $0.03 \mathrm{~L} \mathrm{~min}^{-1}$ flow of dry nitrogen is purged near the mirrors to prevent

98 particle contamination. The flow rate is set to $1 \mathrm{~L} \mathrm{~min}^{-1}$ to pass the cavity with an effective length

99 of $58 \mathrm{~cm}$. A light pulse produced by a Q-switched pulsed laser (532 nm, $100 \mu \mathrm{J}$, duration $11 \mathrm{~ns})$ is

100 injected into the cavity and reflected for 1000 times before leaking out. Overall decay time is

101 recorded by a PMT. The $b_{\text {ext }}$ is determined by:

102

$$
b_{\mathrm{ext}}=\frac{L}{l c}\left(\frac{1}{\tau}-\frac{1}{\tau_{0}}\right)
$$

103 where $L$ is the overall length of the cavity, $l$ is the effective length occupied by particles, $c$ is the 104 speed of light, $\tau_{0}$ is the ring-down time of the cavity filled with particle-free air, and $\tau$ is the 105 recorded decay time.

106 The aerosol scattering coefficient is measured by an integrating nephelometer at three different 107 wavelengths $(450,550$, and $700 \mathrm{~nm})$ with a flowrate of $1.5 \mathrm{~L} \mathrm{~min}^{-1}$. Zero adjusting is done 
108 automatically every $1 \mathrm{~h}$. The nephelometer is calibrated with filtered air and $\mathrm{CO}_{2}$ gas. Truncation 109 correction was done to the measured values, accounting both the lack of illumination at extreme 110 angels and for the slightly non-sinusoidal illumination function of the light source ${ }^{1-3}$. In this work, 111 we applied the measured size distribution from SMPS and V-TDMA (introduced in the Mixing 112 state Section below) for unheated and heated particles and fixed refractive indexes $(k=1.5+0.01 i$ 113 for unheated particles and $k=1.88+0.8 i$ for heated particles) into Mie theory model to calculate 114 angular scattering. By this way, the corresponding scattering error is $\sim 2 \%$.

115 Finally, the scattering coefficient at $532 \mathrm{~nm}\left(b_{\text {scat, } 532}\right)$ is calculated according to:

$$
b_{\text {scat }, 532}=b_{\text {scat, } \lambda}\left(\frac{532}{\lambda}\right)^{-\AA}
$$

117 where $b_{\text {scat, } \lambda}$ is the scattering coefficient at wavelength of $\lambda$, and $\AA$ is the scattering Ångström 118 exponent (SAE) calculated by:

$$
\mathrm{SAE}=-\frac{\ln \left(\frac{b_{\text {scat }, 700}}{b_{\text {scat } 450}}\right)}{\ln \left(\frac{700}{450}\right)}
$$


122 A self-designed volatility tandem differential mobility analyzer (V-TDMA) is employed to detect

123 the mixing state distribution of particles. Briefly, the system consists of two DMAs (model 3081L,

124 TSI Inc.) in tandem with a TD in between, a condensed particle counter (CPC, model 3771, TSI

125 Inc.), and a pump. Particles are size-dependently charged by a bipolar neutralizer and then selected

126 by specific electric field intensity in the upstream DMA1. The bipolar neutralizer exposes the

127 aerosol particles to high concentrations of bipolar ions. Particles passing through the neutralizer

128 quickly reach a bipolar charge distribution. Particles are selected by the intensity of the electric

129 field provided by a high voltage supply connected to the inner cylinder. Particle size is obtained

130 through the diameter-voltage conversion.

131 In this work, the sampled aerosol was firstly dried and then subsequently entered the upstream

132 DMA1. Here, the monodisperse aerosols with mobility diameter $\left(d_{\mathrm{p}}\right)$ of $40,70,100,150,200,300$,

133 and $350 \mathrm{~nm}$ were selected via DMA1 and passed to the TD section at $300{ }^{\circ} \mathrm{C}$ in turn. The size

134 distribution of the after-heated particles were then detected by the downstream DMA2 and CPC.

135 The CPC then counted the particle numbers at a constant flow rate of $0.3 \mathrm{~L} \mathrm{~min}^{-1}$. After a loop of

1367 size bins was completed, ambient samples directly passed to the DMA2 and CPC and an overall

137 size distribution of ambient particles was made (scanning mobility particle sizer, SMPS mode).

138 Measurements were operated alternatively between the unheated SMPS mode and the heated V-

139 TDMA mode, which took around 40 minutes overall. 
140 To reduce the uncertainty brought by the entire evaporation of non-BC particles after heating, 141 we further checked the fractions of BC-containing particles from the SPAMS. The main sampling 142 size range of the SPAMS is in the aerodynamic diameters $\left(d_{\mathrm{va}}\right)$ of $0.2-2.0 \mu \mathrm{m}$. Thus, we selected 143 different size ranges to detect the number fraction of BC-containing particles in each range (Figure 144 S4). The averaged number fractions of BC-containing particles after heating for the size ranges of $145 d_{\mathrm{va}} \leq 0.2 \mu \mathrm{m}, 0.2<d_{\mathrm{va}} \leq 0.5 \mu \mathrm{m}$, and $d_{\mathrm{va}}>0.5 \mu \mathrm{m}$ are $93 \%, 86 \%$, and $79 \%$, respectively. The time146 resolved fractions of $\mathrm{BC}$-containing particles were used to correct the number concentration 147 detected by the V-TDMA. However, the aerodynamic diameters detected by the SPAMS do not 148 correspond to the mobility diameters selected by the DMA as the variation of particle morphology 149 and density. Therefore, the time-resolved fractions of the smallest particle size range $\left(d_{\mathrm{va}} \leq 0.2 \mu \mathrm{m}\right)$ 150 are used to correct the number concentration of particles below $100 \mathrm{~nm}$ detected by the V-TDMA. 151 The time-resolved BC-containing fractions of moderate $\left(0.2<d_{\mathrm{va}} \leq 0.5 \mu \mathrm{m}\right)$ and largest particle size 152 ranges $\left(d_{\mathrm{va}}>0.5 \mu \mathrm{m}\right)$ were likewise used to correct the number concentration of 100-300 $\mathrm{nm}$ and $>$ $153300 \mathrm{~nm}$ particles detected by the V-TDMA, respectively. 
156 In this work, $V_{\text {particle }}$ is the cumulative volume calculated based on the diameter of each size bin 157 from an SMPS scan (60 size bins in total, taken as $\left.d_{\text {particle }}\right)$. After heating at $300{ }^{\circ} \mathrm{C}$, the DMA1 158 selected particles $\left(d_{\mathrm{p}}: 40,70,100,150,200,300,350 \mathrm{~nm}\right)$ shrunk to smaller sizes. The DMA2159 CPC then detected shrunken particle distribution and the after-heating diameter was taken as $d_{\mathrm{c}}$ 160 with 45 size bins in total. We took the 7 selected diameters $\left(d_{\mathrm{p}}\right)$ as the medians to group the 60 size 161 bins in one SMPS scan into 7 size ranges (Figure S5). Exceptions are the first and the last size 162 ranges as the number concentrations of particles smaller than $40 \mathrm{~nm}$ or larger than $350 \mathrm{~nm}$ are too 163 low to be detected, so we took $40 \mathrm{~nm}$ and $350 \mathrm{~nm}$ as the limit then.

164 The shrink factors $\left(S F\right.$, defined by $\left.d_{\mathrm{c}} / d_{\mathrm{p}}\right)$ of 7 selected particles size ranges were used as a factor 165 to constrain the core diameter ( $\left.d_{\text {core }}\right)$ from an SMPS scan following the equation:

$$
d_{\text {core }}=d_{\text {particle }} \times S F=d_{\text {particle }} \times \frac{d_{c}}{d_{\mathrm{p}}}
$$

167 Revised by the $S F$, the $R_{\mathrm{BC}}$ for an SMPS scan can be expressed as:

$$
\begin{aligned}
R_{\mathrm{BC}} & =\frac{\left(\sum d_{\text {particle }}^{3}(i)-\sum d_{\text {core }}^{3}(i)\right) \rho_{\text {coating }}}{\left.\sum d_{\text {core }}^{3}(i)\right) \rho_{\text {core }}} \\
& =\frac{\sum_{i=1}^{60}\left(N_{i} \times d_{p, i}^{3}-\sum_{j=1}^{45} M_{j} \times d_{c, i j}^{3}\right) \times \rho_{\text {coating }}}{\left(\sum_{i=1}^{60} \sum_{j=1}^{45} M_{j} \times d_{c, i, j}^{3}\right) \times \rho_{\text {core }}}
\end{aligned}
$$




$$
=\frac{\sum_{i=1}^{60}\left(N_{i} \times d_{p, i}^{3}-\sum_{j=1}^{45} M_{j} \times d_{p, i}^{3} \times S F_{i, j}^{3}\right) \times \rho_{\text {coating }}}{\left(\sum_{i=1}^{60} \sum_{j=1}^{45} M_{j} \times d_{p, i}^{3} \times S F_{i, j}^{3}\right) \times \rho_{\text {core }}}
$$

171 where $i$ is the number series of size bins in an SMPS scan (up to 60), $j$ is the number series of size

172 bins in the V-TDMA mode (up to 45), $N$ is the number concentration in the SMPS mode, and $M$

173 is the number concentration in the V-TDMA mode. Schematic of the size-resolved mixing state

174 calculation is in Figure S6.

175 The mobility diameter from the DMA could be sensitive to the particle shape, which could 176 overestimate the volume equivalent diameter for non-spherical particles ${ }^{4}$. In this work, most of the 177 observed $R_{\mathrm{BC}}$ (mass ratio) is in the range of $\sim 1-20$. In such scenario, the particle shape factor should 178 be $\sim 1.2-1.8$ (from $196 \mathrm{~nm}$ to $557 \mathrm{~nm}$ in mobility diameter) with the smaller mobility diameter 179 corresponding to the smaller shape factor ${ }^{4}$. In this work, the mode peak in the size distribution by 180 the SMPS is $\sim 60-70 \mathrm{~nm}$. We suppose the shape factor of particles dominated in this size range 181 could be around 1 and the uncertainty induced by the mobility size measurement would be 182 acceptable. 
185 For the DMA1 selected particles $\left(d_{\mathrm{p}}\right)$, the inner core size can be derived either by considering the 186 bulk $R_{\mathrm{BC}}$ or by applying the residual particles size distribution $\left(d_{\mathrm{c}}\right)$ from the DMA2-CPC system. 187 For the first case, all the BC cores are assumed to be equally coated. The inner core diameter $\left(d_{\text {core }}\right)$ 188 is calculated following the equation:

$$
d_{\text {core }}=\sqrt[3]{\frac{\rho_{\text {coating }}}{\left(R_{\mathrm{BC}} \rho_{\text {core }}+\rho_{\text {coating }}\right)} d_{\text {particle }}^{3}}
$$

In this case, the calculation of absorption enhancement of the uniformly coated BC-containing particles $\left(E_{\mathrm{abs}, \text { uniform }}\right)$ was carried out using (1) the size distribution of the whole BC-containing 192 particle $\left(d_{\text {particle }}\right)$ in an SMPS scan, $(2)$ the size distribution of the inner BC core $\left(d_{\text {core }}\right)$ derived from $193 d_{\text {particle }}$ by considering the bulk $R_{\mathrm{BC}},(3)$ the refractive indexes for $\mathrm{BC}$ core and coating materials, 194 which are assumed to be $1.88+0.8 i$ and $1.5+0.01 i$, respectively.

195 For the second case, the diameter of BC core were calculated according to the residual particle 196 distribution after heating. By multiplying $d_{\text {particle }}$ by the $S F$, the resulted $d_{\text {core }}$ which was also used 197 in the calculation of $R_{\mathrm{BC}}$, was applied into the core-shell Mie model. The calculation of absorption 198 enhancement of the particle-resolved coated BC-containing particles $\left(E_{\text {abs,resolved }}\right)$ was carried out 199 by (1) the size distribution of the whole BC-containing particle $\left(d_{\text {particle }}\right)$ in an SMPS scan, $(2)$ the 200 size distribution of the inner BC core $\left(d_{\text {core }}\right)$ derived from $d_{\text {particle }}$ multiplied by the $S F$, (3) the 201 refractive indexes for $\mathrm{BC}$ core and coating materials by assumption of $1.88+0.8 i$ and $1.5+0.01 i$, 
202 respectively. Schematic of various diameters detected from the V-TDMA system and their 203 corresponding function used in the $R_{\mathrm{BC}}$ and $E_{\mathrm{abs}}$ calculation is in Figure $\mathrm{S} 7$. 
206 As discussed in the main text, we assume Mode 1 in the RCT distribution typically corresponds to 207 the fresh particles from local traffic emission with thin coating, which has much stable emission 208 load. Thus, based on the Gaussian fitting of observed RCT distributions, the parameters of $\mu_{1}, \sigma_{1}$, 209 and $A_{1}$ used in the simulation were fixed at $0.04,0.06$, and 1 , respectively. The variable parameters 210 are $\mu_{2}, \sigma_{2}$, and $A_{2}$ for Mode 2, which corresponds to the more aged regional transported air mass. 211 Meanwhile, to make sure there being single variable in each simulation of RCT distribution, the 212 other two parameters are fixed.

213 Variability in RCT was calculated based on the variance of bimodal normal mixture:

$$
\operatorname{Var}=P_{1} \sigma_{1}^{2}+P_{2} \sigma_{2}^{2}+P_{1} P_{2}\left(\mu_{1}-\mu_{2}\right)^{2}
$$

215 where $P_{1}$ and $P_{2}$ are the possibilities of Mode 1 and Mode 2, respectively. In this work, the 216 simulated number concentration of RCT distribution was normalized to $P_{1}+P_{2}=1$. Since the 217 variation of $\sigma_{2}$ is not a key influential factor of $\Delta E_{\text {abs, }}$, we fixed $\sigma_{2}$ at 0.06 and variable $\mu_{2}$ and $A_{2} / A_{1}$ 218 were considered in the simulation and calculation of the variability in RCT. The relationship of 219 variable $\mu_{2}$ and $A_{2} / A_{1}$ with corresponding variability in RCT distribution is shown in Figure S10. 220 Similar to the influence on $\Delta E_{\text {abs }}$, the variability in RCT becomes prominent when $\mu_{2}$ above 0.4 221 and $A_{2} / A_{1}$ at $\sim 1$. 
224 (1) Anderson, T. L.; Covert, D. S.; Marshall, S. F.; Laucks, M. L.; Charlson, R. J.; Waggoner, A. 225 P.; Ogren, J. A.; Caldow, R.; Holm, R. L.; Quant, F. R.; Sem, G. J.; Wiedensohler, A.; Ahlquist, 226 N. A.; Bates, T. S., Performance characteristics of a high-sensitivity, three-wavelength, total 227 scatter/backscatter nephelometer. J. Atmos. Ocean. Tech. 1996, 13, (5), 967-986.

228

229

(2) Anderson, T. L.; Ogren, J. A., Determining Aerosol Radiative Properties Using the TSI 3563 Integrating Nephelometer. Aerosol Sci. Technol. 1998, 29, (1), 57-69.

230

(3) Bond, T. C.; Covert, D. S.; Müller, T., Truncation and Angular-Scattering Corrections for 232 Absorbing Aerosol in the TSI 3563 Nephelometer. Aerosol Sci. Technol. 2009, 43, (9), 866-

(4) Hu, K.; Liu, D. T.; Tian, P.; Wu, Y. Z.; Deng, Z. Z.; Wu, Y. F.; Zhao, D. L.; Li, R. J.; Sheng,

234 J. J.; Huang, M. Y.; Ding, D. P.; Li, W. J.; Wang, Y. Y.; Wu, Y., Measurements of the Diversity 235 of Shape and Mixing State for Ambient Black Carbon Particles. Geophys. Res. Lett. 2021, 48, $236 \quad(17)$. 
239 Table S1. Sampling period, average $\mathrm{PM}_{2.5}$, average $\boldsymbol{E}_{\mathrm{abs}, \mathrm{observed}}$, and average $\boldsymbol{R}_{\mathrm{BC}}$ for Scenario

240 1-1, Scenario 1-2, and Scenario 2 in Figure 2.

\begin{tabular}{|c|c|c|c|}
\hline Episode & Scenario 1-1 & Scenario 1-2 & Scenario 2 \\
\hline Sample period & $\begin{array}{c}\text { 1/1 9:00-1/19 11:00 } \\
\text { (eliminating S1-2\&S2) }\end{array}$ & 1/6 7:00-1/7 20:00 & 1/14 4:00-1/16 20:00 \\
\hline Average $\mathrm{PM}_{2.5}\left(\mu \mathrm{g} \mathrm{m}^{-3}\right)$ & $53.8 \pm 30.0$ & $8.2 \pm 5.8$ & $14.2 \pm 5.6$ \\
\hline Average $E_{\text {abs,observed }}$ & $1.80 \pm 0.29$ & $1.22 \pm 0.09$ & $1.28 \pm 0.16$ \\
\hline Average $\boldsymbol{R}_{\mathrm{BC}}$ & $5.70 \pm 2.39$ & $1.36 \pm 0.41$ & $5.95 \pm 1.87$ \\
\hline
\end{tabular}

241 


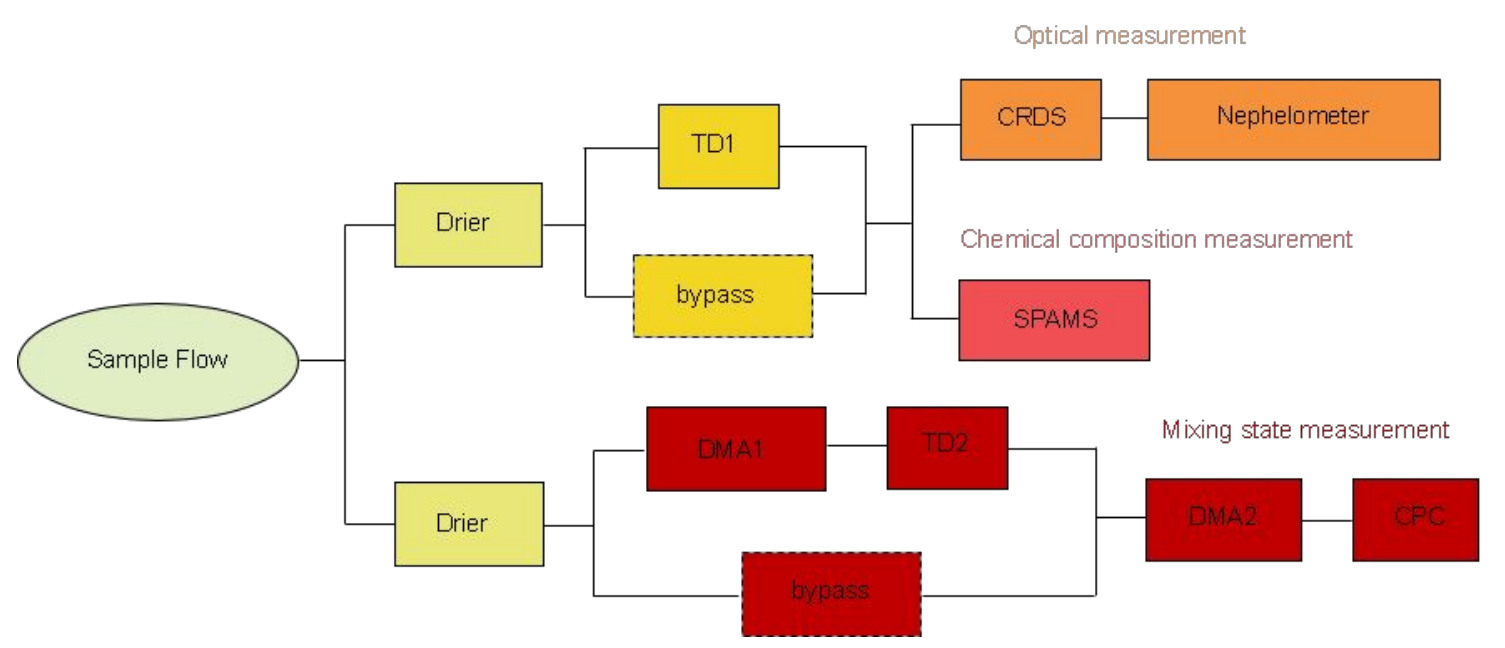

244 Figure S1. Schematic of the instrumental setup. Direct optical measurement includes extinction $245\left(b_{\text {ext }}\right)$ and scattering coefficient $\left(b_{\text {scat }}\right)$ measured by cavity ring-down spectrometer $(\mathrm{CRDS}, \lambda=532$ $246 \mathrm{~nm})$ and nephelometer $(\lambda=450,550$, and $700 \mathrm{~nm})$, respectively. Absorption coefficient $\left(b_{\mathrm{abs}}\right)$ is 247 obtained by subtracting the $b_{\text {scat }}$ from the corresponding $b_{\text {ext }}$. Single-particle aerosol mass 248 spectrometer (SPAMS) is used to measure the chemical composition at single-particle level. A 249 thermodenuder (TD1) is used to remove the volatile coating material by heating at $300^{\circ} \mathrm{C}$. Every $25010 \mathrm{~min}$, the optical property and chemical composition measurement system switches between the 251 unheated bypass line and the heated TD1 line. Particle mixing state measurement is achieved by a 252 tandem differential mobility analyzer (TDMA). Another thermodenuder (TD2) heating at $300{ }^{\circ} \mathrm{C}$ 253 is in-line between the DMA1 and DMA2. The combination of TDMA and TD2 constituted the 254 volatility tandem differential mobility analyzer (V-TDMA). When particles directly go through 255 the bypass line and get into DMA2 and condensation particle counter (CPC), the function of the 256 V-TMDA converts into a scanning mobility particle sizer (SMPS). For each loop, the DMA1 257 selected 7 diameters $(40,70,100,150,200,300$, and $350 \mathrm{~nm})$ of particles, and the SMPS scans 258 were made in-between. 


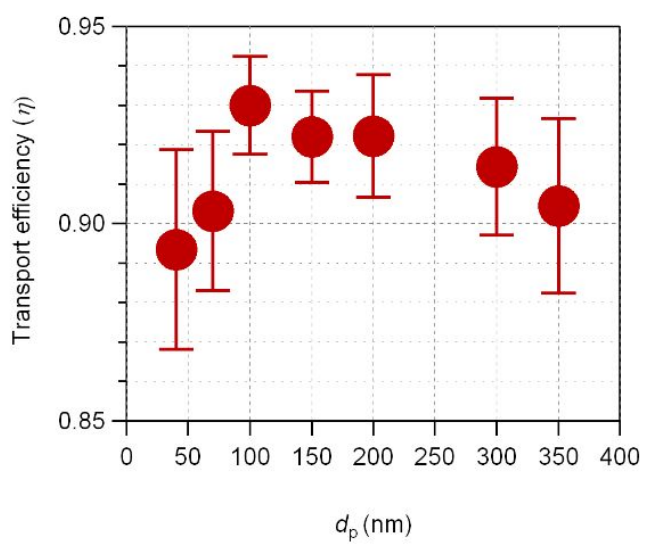

259

260 Figure S2. Transport efficiency $(\eta)$ of $\mathrm{NaCl}$ in the thermodenuder (TD) at $300{ }^{\circ} \mathrm{C}$ as a 261 function of selected diameters. A bypass line in parallel with the TD was used as a reference for 262 the number concentration of unheated particles. The $\eta$ was determined by the number 263 concentration ratio of the heated and unheated particles. 

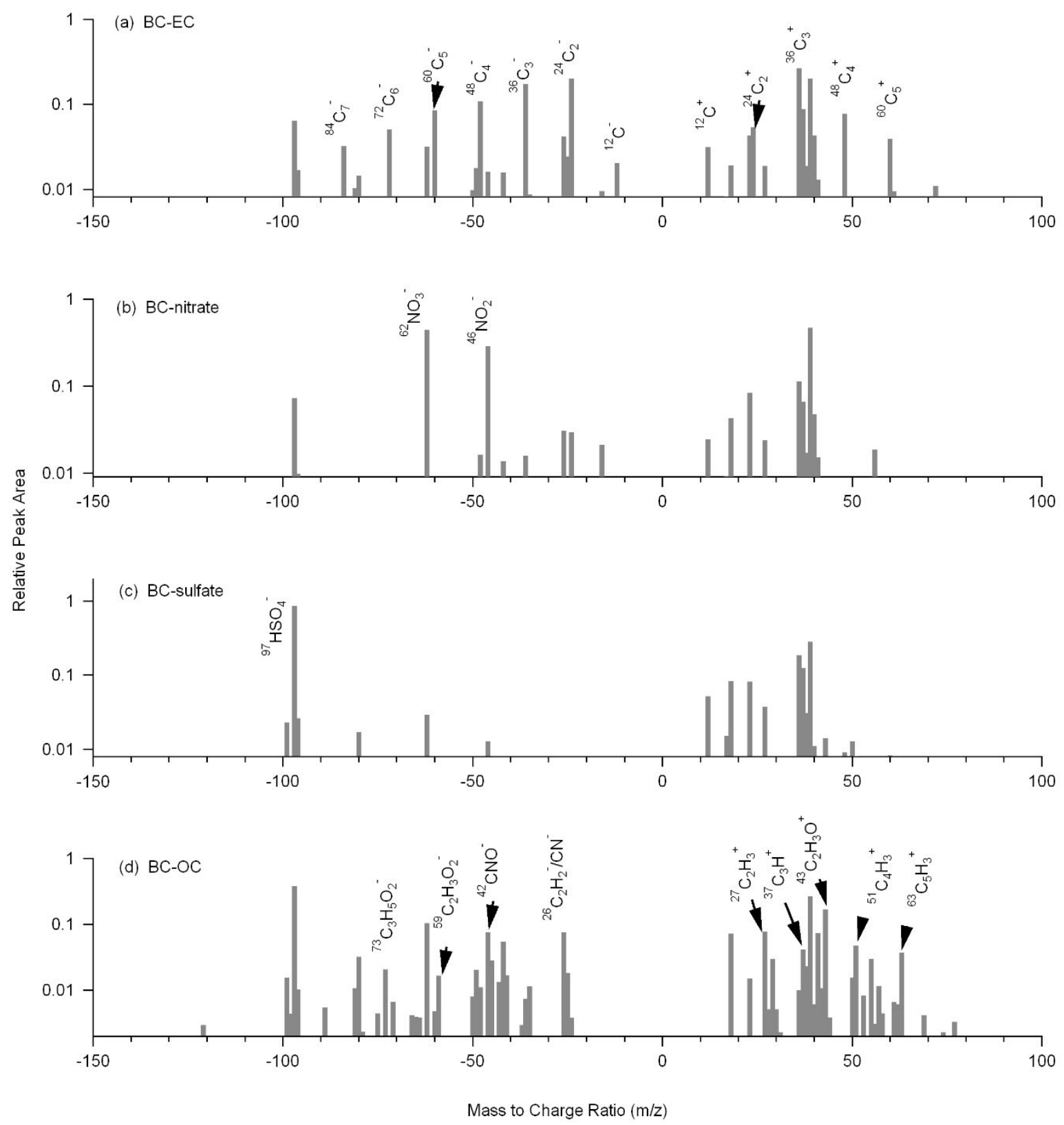

266 Figure S3. Average mass spectra of BC-containing particle types. (a) BC-EC. (b) BC-nitrate.

267 (c) BC-sulfate. (d) BC-OC. The name of a particle type reflects the dominant chemical species. 


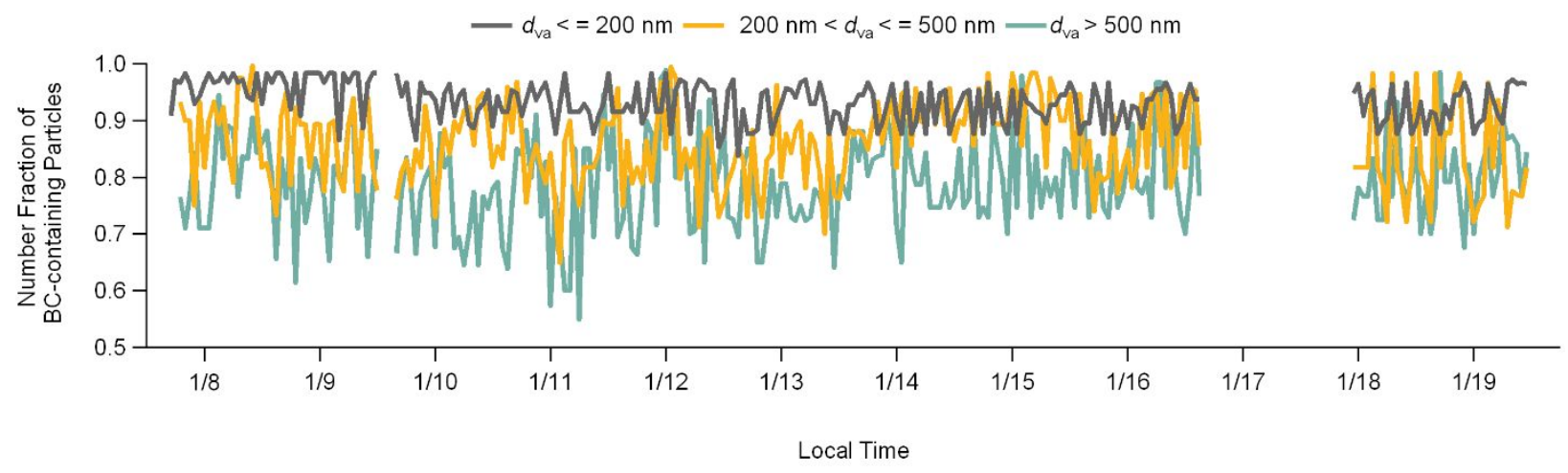

268

269 Figure S4. The number fractions of BC-containing particles for different aerodynamic 270 diameters from the SPAMS. 


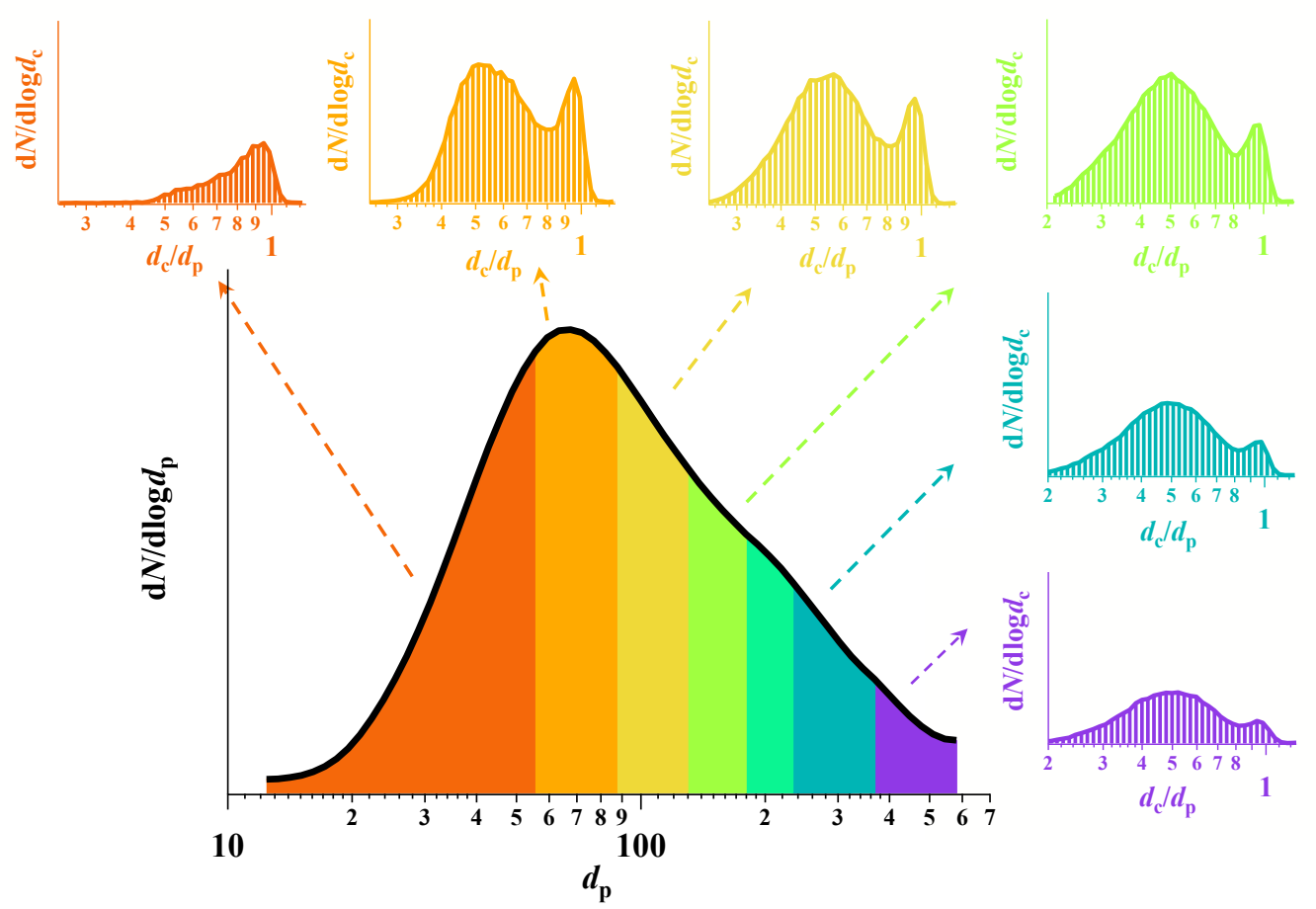

273 Figure S5. Example of the size distribution of an SMPS scan corrected by the shrink factor $274\left(d_{\mathrm{c}} / d_{\mathrm{p}}\right)$ for different size ranges.

275 


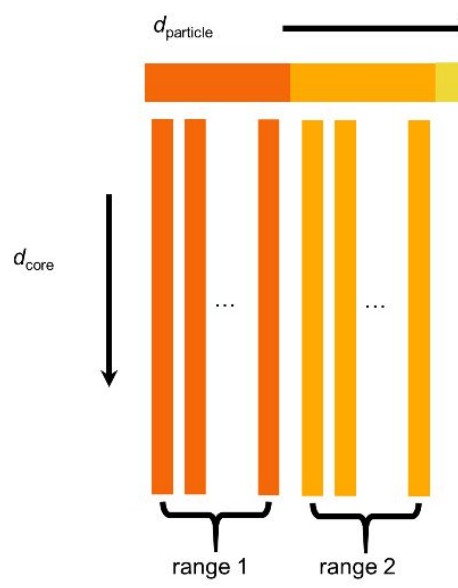

276
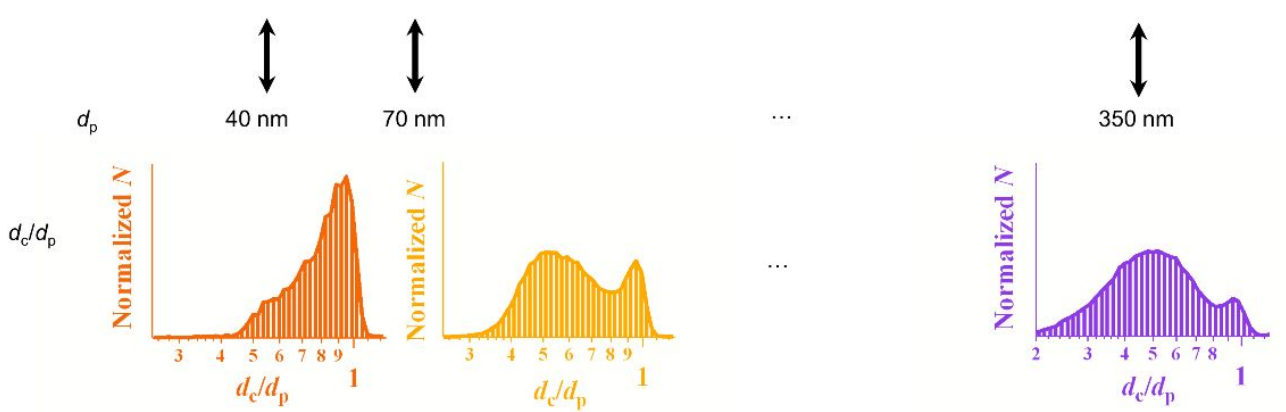

277 Figure S6. Schematic of the size-resolved mixing state calculation.

278 


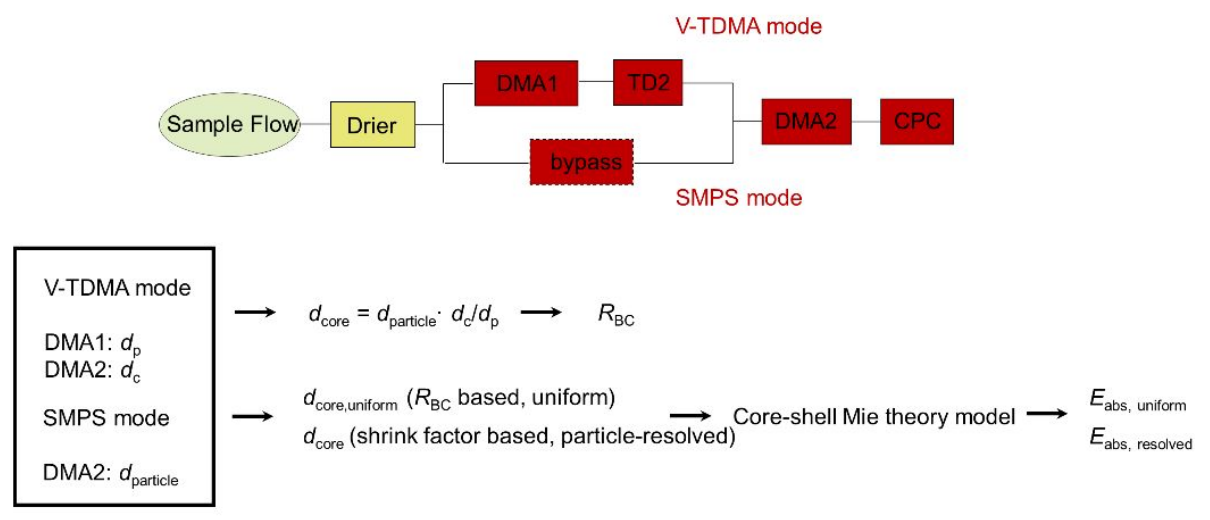

Figure S7. Schematic of different diameters detected from the V-TDMA system and their corresponding function used in the $\boldsymbol{R}_{\mathrm{BC}}$ and $\boldsymbol{E}_{\mathrm{abs}}$ calculation. In the V-TDMA mode, the DMA1 selected particle mobility diameter $(40,70,100,150,200,300$, and $350 \mathrm{~nm})$ is termed as $d_{\mathrm{p}}$, and residual particle diameter after heated (detected by the DMA2) is termed as $d_{\mathrm{c}}$. In the SMPS mode,

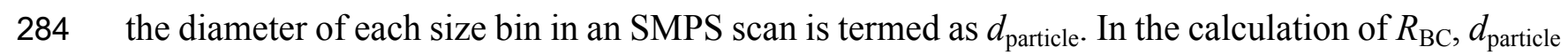
285 is constrained by the shrink factor (defined by $d_{\mathrm{c}} / d_{\mathrm{p}}$ ) for different size ranges, to get the inner BC 286 core size $\left(d_{\text {core }}\right)$. In the calculation of $E_{\text {abs }}$, the BC core size can be derived from $d_{\text {particle }}$ either by 287 considering the $R_{\mathrm{BC}}$ or by multiplying the particle-resolved shrink factor. The $R_{\mathrm{BC}}$-based or shrink288 factor-based BC core size $\left(d_{\text {core, uniform }}\right.$ or $\left.d_{\text {core }}\right)$ were input to the core-shell Mie theory model to 289 derive the absorption enhancement of the uniformly/particle-resolved coated BC-containing 290 particles ( $E_{\text {abs,uniform }}$ or $E_{\text {abs,resolved }}$ ). 

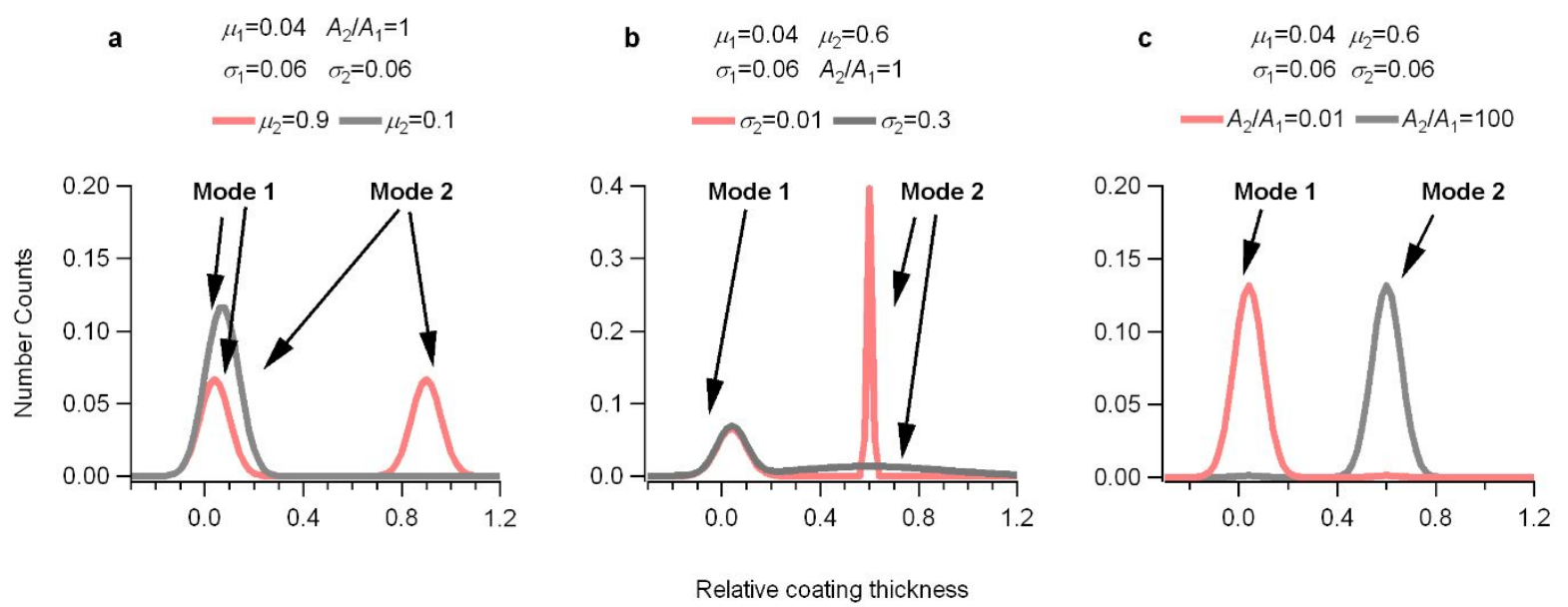

292 Figure S8. Simulated relative coating thickness distributions with variable parameters. The

293 simulated relative coating thickness (RCT) distribution is a combination of two Gaussian 294 distributions. The function of a Gaussian distribution is defined by parameters including 295 mathematical expectation $(\mu)$, standard deviation $(\sigma)$, and the magnification $(A)$, which can 296 influence the mode center, mode dispersion, and mode area. The parameters for Mode 1 are fixed $297\left(\mu_{1}=0.04\right.$ and $\left.\sigma_{1}=0.06\right)$. The RCT distribution with variable $\mu_{2}, \sigma_{2}$ and $A_{2} / A_{1}$ are shown in a-c, 298 accordingly. Parameters used in the figures (pink and gray lines) are the limit Gaussian fitted 299 values based on the observed RCT data. 

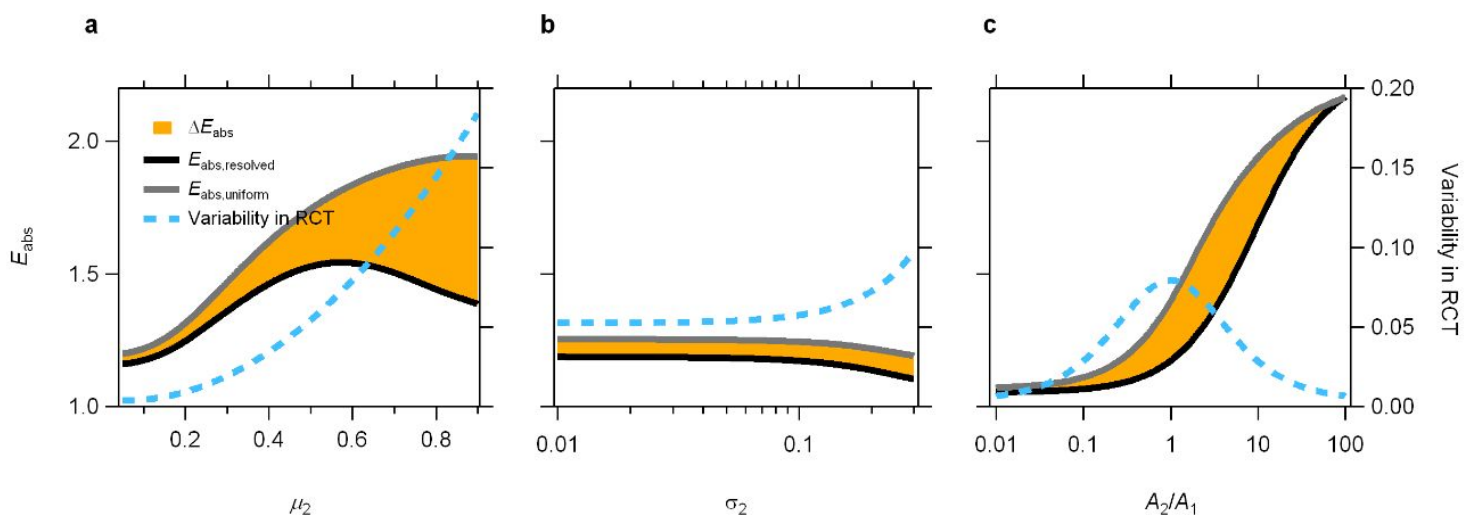

301 Figure S9. Simulated absorption enhancement for particles based on uniform coating 302 thickness ( $\left.E_{\text {abs,uniform }}\right)$ and relative coating thickness (RCT) distribution $\left(\boldsymbol{E}_{\mathrm{abs}, \text { resolved }}\right)$. The RCT 303 distribution is parameterized by a combination of two Gaussian distributions. Parameters for the 304 first Gaussian distribution $\left(\mu_{1}\right.$ and $\left.\sigma_{1}\right)$ are fixed. Modeled $E_{\text {abs,uniform }}$ and $E_{\text {abs,resolved }}$ with variable $\mu_{2}$ 305 (a), $\sigma_{2}(\mathbf{b})$, and $A_{2} / A_{1}$ (c) is based on core-shell Mie theory. Limits used for different parameters 306 are based on the observed RCT data. The colored areas represent the absorption enhancement 307 difference ( $\left.\Delta E_{\mathrm{abs}}\right)$ between $E_{\mathrm{abs}, \text { uniform }}$ and $E_{\mathrm{abs}, \text { resolved }}$. Variability in the simulated RCT is shown on 308 right axis. 


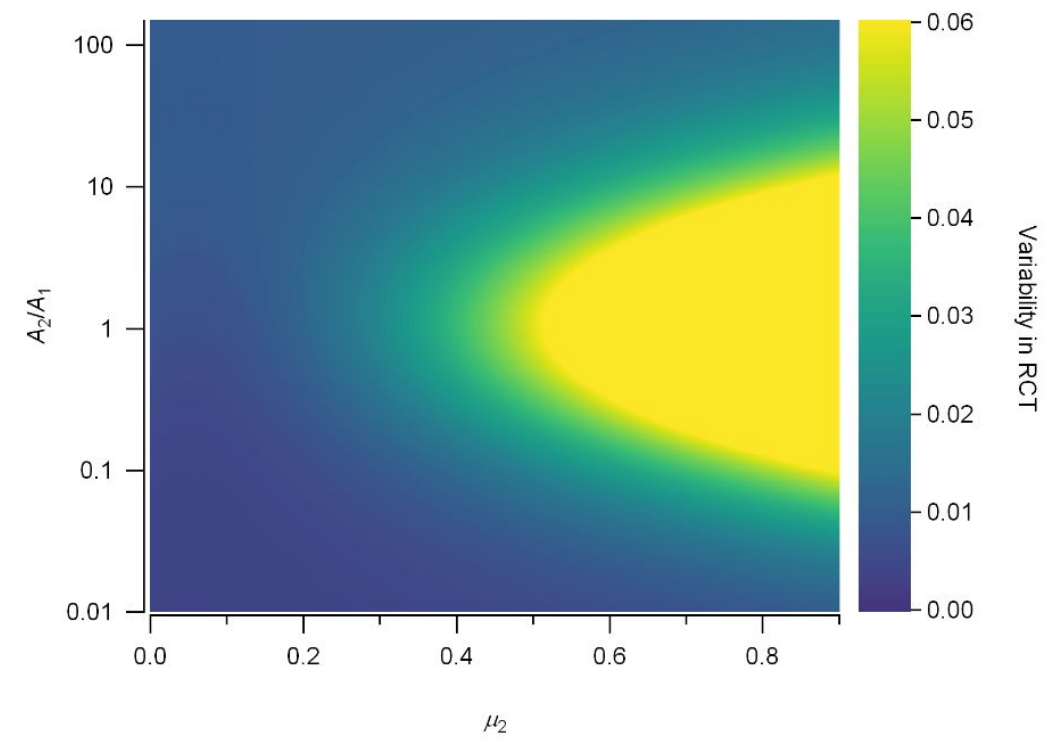

309

310 Figure S10. Variability in RCT distribution as a function of $\mu_{2}$ and $A_{2} / A_{1}$. 


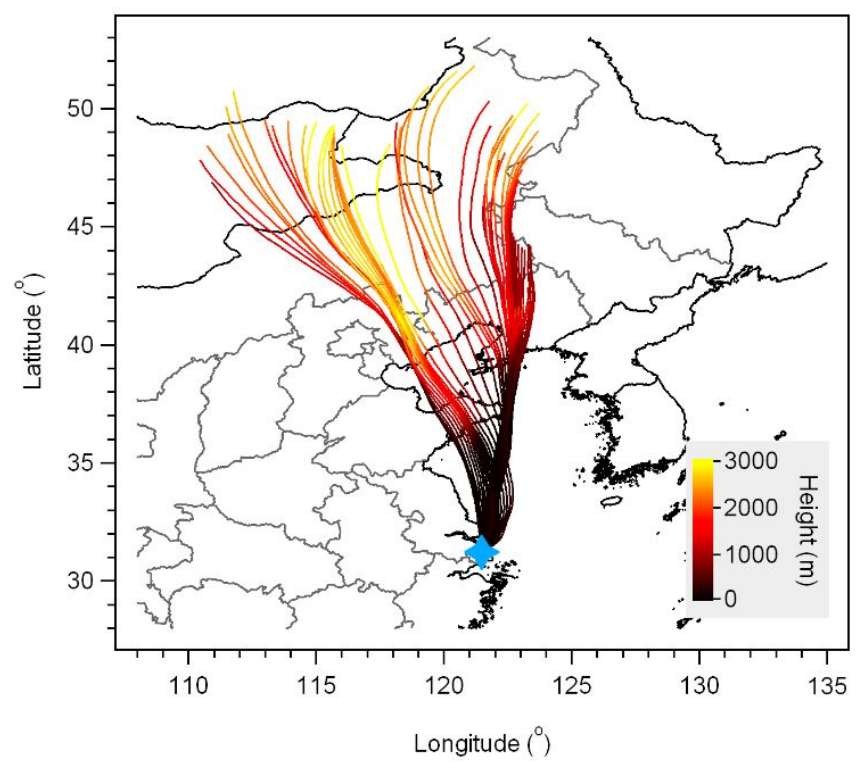

312

313 Figure S11. The HYSPLIT 48 hour air mass backward trajectories at 50 m arrival height

314 ending at 20:00 UTC on 16 January in Shanghai. 